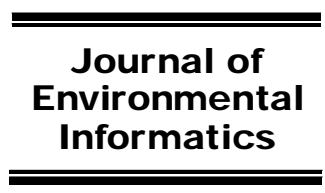

www.iseis.org/jei

\title{
A Note on Baffle Orientation in Long Ponds
}

\author{
K. Sookhak Lari ${ }^{1,2, *}$ \\ ${ }^{I}$ Centre for Environmental Risk Assessment and Remediation, University of South Australia, \\ Mawson Lakes Campus, Mawson Lakes, SA 5095, Australia \\ ${ }^{2}$ CSIRO Land and Water, Private Bag No. 5, Wembley WA 6913, Australia
}

Received 11 August 2011; revised 25 May 2012; accepted 20 September 2012; published online 27 June 2013

\begin{abstract}
This paper assesses the general idea of implementing transversal baffles to improve hydraulic efficiency of rectangular ponds used in water and wastewater treatment processes. The paper concentrates on long ponds with the length-to-width ratio of $4: 1$. Three different scenarios of plain (baffle-less) pond and ponds with four transversal and two longitudinal baffles were considered. A two dimensional Computational Fluid Dynamics (CFD) conservative tracer study was performed. Results showed that the longitudinal layout of the baffles yielded to a hydraulic regime closer to the plug-flow condition, while application of limited number of transverse baffles in long ponds showed an adverse effect on the overall hydraulic performance. Such baffles layout yielded to increased dispersion, as well as comparable dead zones in comparison with the plain pond. A three dimensional analysis was also conducted to evaluate the effect of volumetric dispersion, which yielded to the same results. Possible reasons for this phenomenon were discussed. Results suggest that application of limited number of transverse baffles in long ponds needs extra consideration.
\end{abstract}

Keywords: CFD, longitudinal baffles, long ponds, transverse baffles, water and wastewater

\section{Introduction}

Plug-flow condition is the desired hydraulic regime in various physical, chemical and biological treatment processes of water and wastewater (chap. 4, Tchobanoglous et al., 2003). For instance, waste stabilization ponds are ideally designed as plug flow reactors which provide uniform hydraulic retention time (HRT) for removal of biochemical oxygen demand (BOD, the oxygen needed for completion of an aerobic biological process) (Wood et al., 1998; Persson, 2000). In this case, each control volume of the fluid which carries passive scalars (like dilute solute mass) will have identical HRT to the pond. Consequently, each molecule of the scalar will experience the pond nominal HRT $\left(\mathrm{HRT}_{\mathrm{N}}\right.$ ) (chap. 5, Crittenden et al., 2005).

On the other hand, what happens in reality generally differs from the ideal plug-flow condition. Thermal stratification (Sweeny et al., 2005), wind effect (Banda et al., 2006) and inlet and outlet hydraulic conditions (Persson, 2000) will usually have two adverse effects on the overall performance of the pond. First, these parameters may create dead zones in ponds, which are the regions in which the mass is trapped in a circulating flow (pp. 1081, Crittenden et al., 2005). These zones reduce effective volume of the pond and consequently, the real (or mean) HRT $\left(\mathrm{HRT}_{\mathrm{R}}\right)$ will be less than $\mathrm{HRT}_{\mathrm{N}}$.

\footnotetext{
${ }^{*}$ Corresponding author. Tel.: +61 893336302 ; fax: +61 893336302.
}

E-mail address: Kaveh.SookhakLari@unisa.edu.au (K. Sookhak Lari).

ISSN: 1726-2135 print/1684-8799 online

(C) 2013 ISEIS All rights reserved. doi:10.3808/jei.201300240
Second, existence of molecular, turbulence and mechanical dispersion causes each control mass of the scalar to experience a HRT which may differ significantly from $\mathrm{HRT}_{\mathrm{R}}$ (chap. 5, Crittenden et al., 2005).

Both of the mentioned problems (reduced $\mathrm{HRT}_{\mathrm{R}}$ and increased variance of the HRT spectrum) yield to adverse effects on hydraulic performance of the pond. For instance, in BOD removal process in facultative ponds, if a control mass remains less than $\mathrm{HRT}_{\mathrm{N}}$ in the pond, the desired BOD removal is not achievable. On the other hand, if the control mass remains longer than the desired $\mathrm{HRT}_{\mathrm{N}}$, the system may shift to an anaerobic condition (Salter et al., 2000).

One of the passive methods to circumvent such problems is making use of various types of barriers such as berms, artificial islands and baffles (Persson, 2000). Such constructions, if properly designed, distribute the flow over the entire cross section of the pond and consequently, the hydraulic performance of the pond is modified.

Several experimental and numerical studies on the effect of pond shape and baffle orientation on the overall performance of the pond have been conducted during the recent decades (e.g. Wood et al., 1995; Ta, 1997; Ta, 1999; Vega et al., 2003; Shilton and Mara, 2005; Shilton et al., 2008). Generally, these studies have demonstrated that one of the key parameters for improving hydraulics of plain ponds is increasing length-to-width (LtW) ratio of the pond. For the case of baffled ponds, it is shown in the literature that implementing transversal baffles in short ponds (with LtW ratio about 2:1) modifies the effective flow path and prevents short-circuits (e.g. Persson, 2000). In this case, implementing 


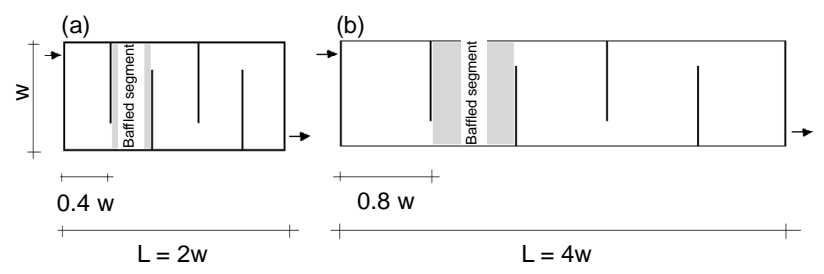

Figure 1. Application of limited transversal baffles in short and long ponds.

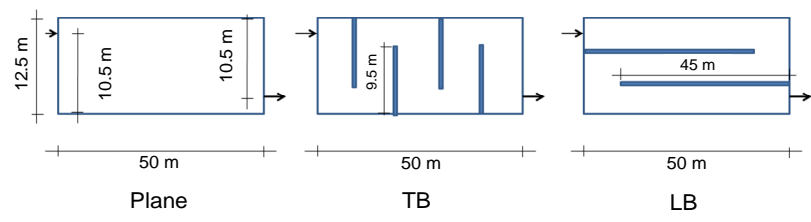

Figure 2. 2D geometries under consideration. The thickness of baffles is $25 \mathrm{~cm}$. Figure is not to scale.

a certain number of baffles increases the LtW of each baffled segment, as shown in Figure 1, in comparison with the overall $\mathrm{LtW}$ ratio of the pond. Consequently, the baffled pond may be considered as a series of baffled segments with higher LtW ratio. However, this may not be the case for longer ponds. Figure 1 shows a counter-example.

Pond $a$ in Figure 1 is a short pond with a LtW ratio of 2:1. On the other hand, the LtW ratio for pond $b$ is $4: 1$. Four transversal baffles are implemented in both ponds. Consequently, the LtW ratio of each baffled segment in ponds $a$ and $b$ is $2.5: 1$ and $1.25: 1$ respectively (note that due to the flow direction, the length of each baffled segment is identical to the pond width). This implies that while implementing four baffles changes pond $a$ to a sequence of baffled segments with higher LtW ratio, such quantity and orientation of baffles in pond $b$ yields to baffled segments with a lower LtW ratio than the original pond.

Based on the discussion above, the aim of this paper is to evaluate potential effects of implementing limited number of transversal baffles in long ponds. In practice, a two dimensional (2D) study compares performance of ponds with LtW of baffled segments lower than the original pond with ponds in which this ratio is higher. The comparison is conducted with respect to the difference between $\mathrm{HRT}_{\mathrm{R}}$ and $\mathrm{HRT}_{\mathrm{N}}$. The dispersion characteristics of each pond is also analyzed. Results are also compared with the counterpart values in a plain pond. Finally, the effect of pond depth is also evaluated in a three dimensional (3D) study.

\section{Problem Description}

Generally, 2D ponds with a LtW ratio of $4: 1$ are considered here (Figure 2). Inlet condition of all the ponds comprises a uniform flow with a width of $1 / 40$ the pond width, located at the upper left corner. Reynolds number $\left(R_{e}=2 U \delta / v\right.$, where $U$ is the average velocity $\left[\mathrm{LT}^{-1}\right], \delta$ is the radius [L] and $v$ is the kinematic viscosity $\left[\mathrm{L}^{2} \mathrm{~T}^{-1}\right]$ (Bird et al., 2001)) is assumed to be 5000 at the inlet. Outlet is located at the lower right corner, comprising the same geometry of inlet. The ponds have $\mathrm{HRT}_{\mathrm{N}}=1.4$ day $(d)$. Three internal layouts are considered for the pond; plain pond, pond with two longitudinal baffles (referred to as LB pond from this point forward) and pond with four transverse baffles (referred to as TB pond from this point forward). In order to evaluate hydraulic performance of the ponds, a pulse of conservative scalar solution with a concentration equal to 1 is injected at the inlet. The injection period is 2 seconds. It is aimed to trace the path of passive scalar solution and evaluate the hydraulic performance of the three mentioned ponds.

\section{Governing Equations}

Steady-state Reynolds-averaged Navier-Stokes (RANS) equations are used to model the flow (chap. 10, Pope, 2000). The eddy viscosity term in RANS equations is closed by the Low-Re number (LRN) Launder-Sharma model. This model has shown acceptable performance for semi-complex geometries like backward steps and corners (Bergmann and Fiebig, 1999). In order to keep this paper short, the reader is referred to study of Rodi and Mansour (1993) for in-detail description and governing equations of various LRN models.

The Launder-Sharma LRN model which is implemented in this study is built in OpenFOAM CFD package. OpenFOAM is a well-established, open-source, finite-volume, numerical package which includes various models for different transport phenomena (OpenCFD, 2008). Once the hydraulic modeling is finished, velocity and eddy diffusivity $\left(D_{T}=v_{T} / S c_{T}\right.$, where $v_{T}$ is the turbulent viscosity $\left[\mathrm{L}^{2} \mathrm{~T}^{-1}\right]$ and $S c_{T} \approx 1$ is the turbulent Schmidt number (Sookhak Lari et al., 2010; Van Reeuwijk and Sookhak Lari, 2012)) profiles are defined. Consequently, it is possible to solve the mass transport equation (chap. 21, Bird et al., 2001):

$$
\frac{\partial \mathrm{c}}{\partial t}+\vec{v} \cdot \nabla c=\nabla \cdot\left[\nabla\left(\left(D+D_{T}\right) c\right)\right]
$$

where $c$ is the concentration $\left[\mathrm{ML}^{-3}\right], D$ is the molecular diffusion coefficient $\left[\mathrm{L}^{2} \mathrm{~T}^{-1}\right], \vec{v}$ is the velocity vector $\left[\mathrm{LT}^{-1}\right]$, and $t$ represents time [T]. All of the equations (RANS and mass transport) are subjected to no-slip boundary condition at the walls (Weigand, 2004).

The domains in Figure 2 are discretized by clustered finite volume grids in which more resolution is provided near the boundaries to capture the viscous sublayer (Pope, 2000). Total numbers of 10000, 20000 and 20000 cells are used for the plain, TB and LB ponds respectively. A maximum relative residual equal to $10^{-6}$ is also considered as the convergence criterion for all the variables.

\section{Results}

Figure 3 shows the plume of the passive scalar concentration of all three ponds in different time intervals. As it is seen in this figure, the plumes in plain and TB pond travel 
$0.00 \mathrm{e}+0.001 \quad 1.30 \mathrm{e}-005 \quad 2.50 \mathrm{e}-005 \quad 3.8 \mathrm{e}-005 \quad 5.0 \mathrm{e}-005$

(1)

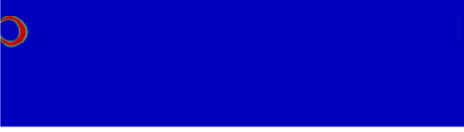

(2)

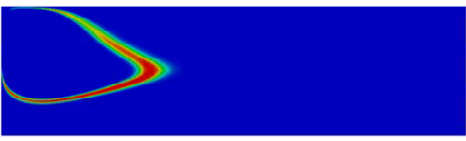

(3)

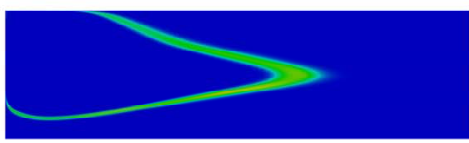

(4)

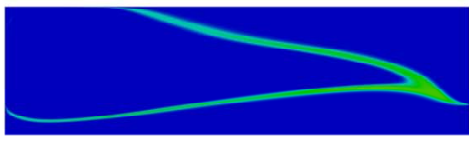

(5)

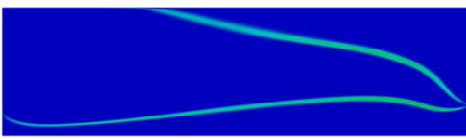

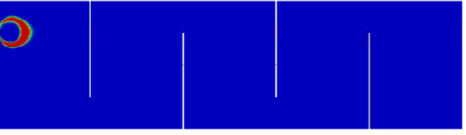
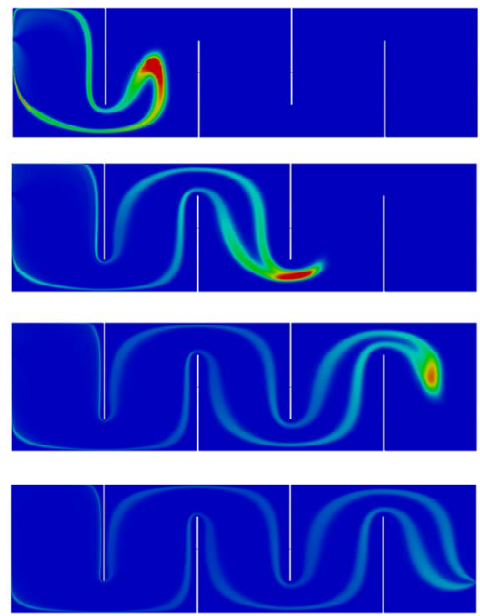
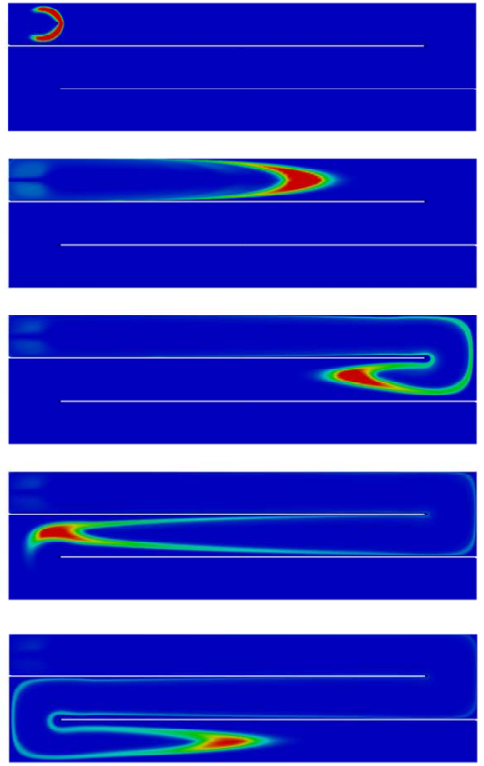

Figure 3. Scalar concentration in different time intervals (colored figure): 1) $20 \mathrm{~min}, 2$ ) 0.25d, 3) 0.5d, 4) 0.75d, 5) 1 day.

much faster than the LB pond. While the HRT of the plumes core in plain and TB pond is about $0.7 \sim 0.8$ day, this time is near 1.3 days in $\mathrm{LB}$ pond. This issue implies that the volume of the dead zone in plain and TB pond is almost equal. This volume is much lower in LB pond. In other words, the $\mathrm{HRT}_{\mathrm{R}}$ in $\mathrm{LB}$ pond is near the $\mathrm{HRT}_{\mathrm{N}}=1.4$ days.

As was discussed before, in addition to the dead zones (which affects the $\mathrm{HRT}_{\mathrm{R}}$ ), another problem which occurs in ponds is dispersion. This problem is studied in Figure 4 in which results of the instantaneous concentration at the outlet are plotted versus time. As it is seen in this figure, the tail of the scalar concentration plume is highly extended in plain and TB pond. On the other hand, the LB pond shows a more uniform concentration plume. This implies that the dispersing property of the LB pond is less than the other two ponds.

Defining $\mathrm{HRT}_{\mathrm{R}}$ and variance as:

$H R T_{R}=\frac{\int_{0}^{\infty} t c(t) d t}{\int_{0}^{\infty} c(t) d t}$

$\sigma^{2}=\frac{\int_{0}^{\infty}\left(t-H R T_{R}\right)^{2} c(t) d t}{\int_{0}^{\infty} c(t) d t}$

and $e=\frac{H R T_{R}}{H R T_{N}}$

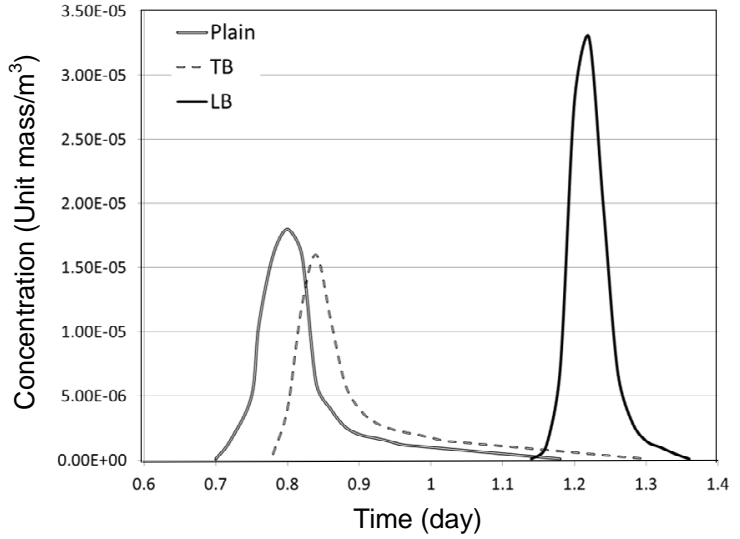

Figure 4. Instantaneous concentration at outlet (2D).

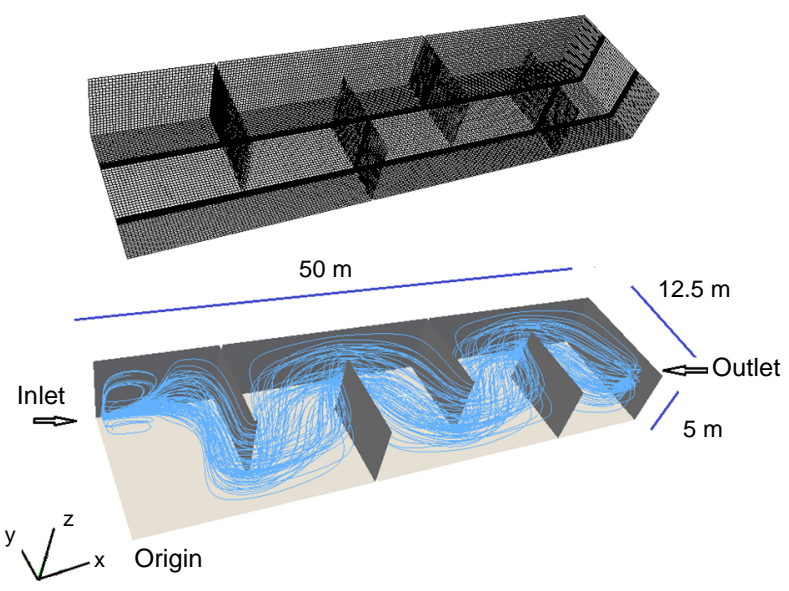

Figure 5. Up: 3D finite volume mesh; Down: Tracer streamlines. (colored figure). Two of the side walls are intently not demonstrated. 


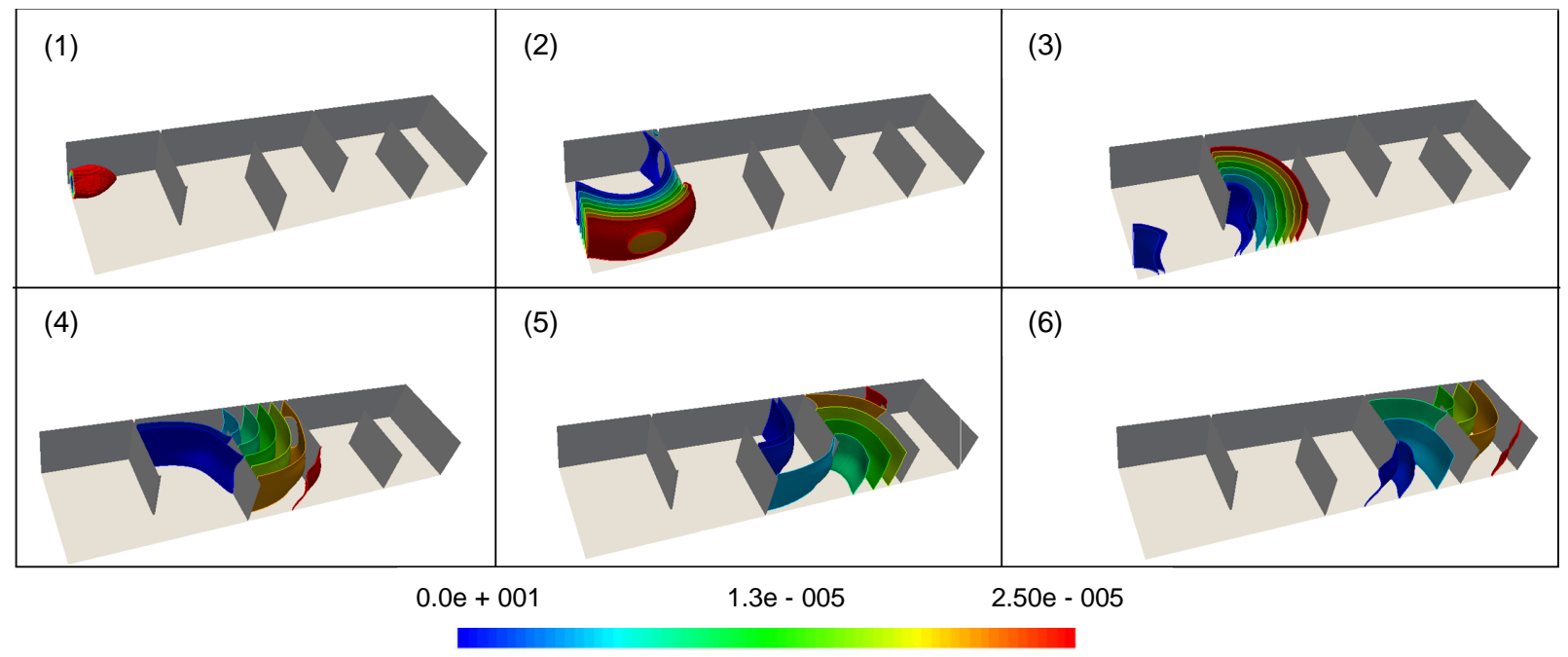

Figure 6. Concentration contours in different time intervals (colored figure). 1) $20 \mathrm{~min}, 2) 0.15 \mathrm{~d}, 3)$ 0.3d, 4) 0.45d, 5) $0.6 \mathrm{~d}, 6) 0.75 \mathrm{~d}$.

Table 1. HRT, Variance and Effective Volume of Ponds

\begin{tabular}{llll}
\hline Internal layout & HRT_R (day) & $\sigma^{2}\left(\right.$ day $\left.^{2}\right)$ & $\mathrm{e}$ \\
\hline Plain & 0.798 & 0.81 & 0.57 \\
TB & 0.871 & 0.96 & 0.62 \\
LB & 1.22 & 0.16 & 0.87 \\
\hline
\end{tabular}

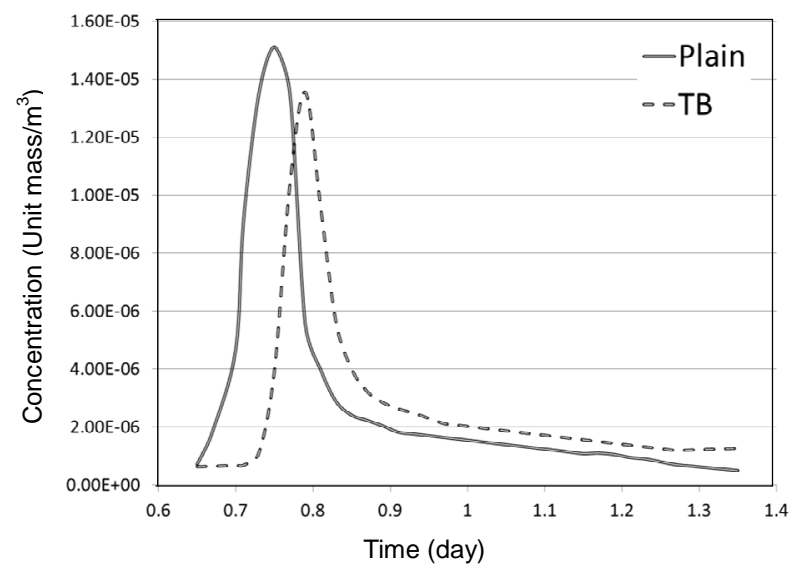

Figure 7. Instantaneous concentration at outlet (3D).

as the effective volume fraction, these values are calculated for three ponds and shown in Table 1. As it is seen in this table, application of four transverse baffles in a pond with a LtW ratio equal to 4:1 does not show a considerable influence on reducing dead zones, since $\mathrm{HRT}_{\mathrm{R}} \mathrm{S}$ for plain and $\mathrm{TB}$ pond are 0.798 and $0.871 \mathrm{~d}$ respectively.

In addition, such orientation yields to higher dispersion (or higher variance) in comparison to the plain pond. For the mentioned layout of baffles, the LtW ratio of each baffled segment is less the LtW ratio of the pond itself (1.25:1 vs. $4: 1)$. Considering the TB pond as a sequence of plain ponds with LtW ratio equal to $1.25: 1$, this issue causes numerous considerable dead zones in each baffled segment of the TB pond. Furthermore, each segment of the TB pond is not long enough so that the flow becomes fully developed (i.e., the variation in the streamwise direction becomes negligible). Consequently, sharp gradients of velocity occur frequently. This ends to a higher dispersion in TB pond.

The LtW ratio of each baffled segment of the LB pond is $12: 1$. This ratio is much higher than the plain pond $\mathrm{LtW}$ ratio $=$ $4: 1$. Considering the LB pond a sequence of plain ponds with LtW ratio of $12: 1$, this means that performance of each segment is increased in comparison with the plain pond.

\section{Three Dimensional Verification}

The study presented in previous section focused on the performance of the three ponds in a horizontal section. However, existence of the vertical mixing due to molecular and turbulence diffusion may affect the results (Talvy et al., 2007). In order to perform a verification on the most critical finding of the 2D study (i.e., poorer performance of the TB pond in comparison with the plain pond), a 3D study is conducted in this section. The geometries of plain and TB ponds introduced in Figure 2 are now modified to 3D ponds with a depth of $5 \mathrm{~m}$. The position of inlet and outlet are not changed in horizontal section. They are also located at the half-depth of the ponds. Atmospheric boundary condition is applied at the upper faces of the ponds.

As a representative, Figure 5 shows the applied finite volume mesh for the TB pond, including 460800 cells. In order to keep the $\mathrm{HRT}_{\mathrm{N}}$ identical for both 2D and 3D cases, $\mathrm{Re}=25000$ is applied at the circular inlet. The figure also demonstrates particles path line for a number of 100 particles released at the entrance. This demonstration visualizes active parts of the pond.

The mass transport study conducted in previous section is now performed for the introduced $3 \mathrm{D}$ geometries. Similar to 
the previous case, a passive scalar stream with the concentration of unity is injected at the inlet of both plain and TB ponds for 2 seconds and the instantaneous scalar concentration is measured at the outlet.

Figure 6 shows contours of the concentration in TB pond for different time intervals. This seen in the figure that (as expected) the effect of depth in dispersion is significant (since the contours are extended throughout the depth). The same phenomenon was also observed for the plain pond (not shown). To quantify such phenomenon and compare it for both plain and TB ponds, the instantaneous concentration at the outlet is plotted in Figure 7. The figure indicates that the findings in previous section are qualitatively confirmed.

Using Equation 2, the value of $\mathrm{HRT}_{\mathrm{R}}$ for the $3 \mathrm{D}$ plain and TB ponds are 0.76 and 0.82 respectively, showing a faster average transport and therefore, a poorer performance rather than the $2 \mathrm{D}$ case. Furthermore, the values of $\sigma^{2}$ for the two ponds are 0.83 and 0.97 respectively which are again higher than their 2D counterpart values. This finding shows the positive effect of the third dimension in increasing the dispersion which is qualitatively in agreement with other studies (Talvy et al., 2007). However, the fact which remained untouched in both 2D and 3D cases is poorer performance of the TB pond under study than the plain pond.

\section{Conclusions}

Several experimental and numerical studies have been done to evaluate optimized number and orientation of baffles (as well as other passive techniques) to modify hydraulic performance of rectangular ponds. In practice, the most similar flow pattern to the plug-flow condition is desirable. In this case, $\mathrm{HRT}_{\mathrm{N}}$ and $\mathrm{HRT}_{\mathrm{R}}$ of the pond under study should be identical. In addition, pond dispersive property should be minimized as well. Following the same objectives, the current paper aimed to evaluate preferred baffle orientation in long ponds.

It was discussed that implementing limited number of transversal baffles in long ponds causes the LtW value of each baffled segment to be less than the pond overall LtW. A case of transversally baffled pond with the LtW value of the baffled segments less than the overall LtW (introduced as TB pond) was considered. The 2D numerical analysis showed that the TB long pond does not demonstrate a significant improvement in comparison with a plain pond. Dead zones in plain and TB pond were 43 and $38 \%$ (determined as $1-e$, see Equation 4) of the pond volume respectively. This value was $13 \%$ in a longitudinally baffled pond (introduced as LB pond) of the same size but higher segmental LtW than the overall LtW. In addition, both plain and TB pond showed a large dispersion (variance of the concentration plume) in comparison with the LB pond. Consequently, it was discussed that the LB pond shows better plug-flow behavior in comparison with the other two ponds,

In order to spot more light on the results, the cases of plain and TB pond were modified in a $3 \mathrm{D}$ study to consider the effect of the pond depth. Results showed higher dispersion and lower $\mathrm{HRT}_{\mathrm{R}}$ in both ponds in comparison with the $2 \mathrm{D}$ simulation. However, the results remained unchanged with respect to the better performance of the plain pond in comparison with the TB pond.

Based on the results of study, it is suggested that complementary numerical and experimental studies are performed on implementation of limited transverse baffles in long ponds. Possible effects of the inlet and outlet position, wind, thermal stratification and other parameters such as variations in flow should be included as well. At this stage, it is suggested that extra consideration is spent for using such layout of baffles in field applications.

\section{References}

Banda, C., Sleigh, P., and Mara, D. (2006). CFD-based design of waste stabilization ponds; significance of wind velocity. In proceeding of the 7th IWA specialists Group Conference on Waste Stabilization Ponds, Asian Institute of Technology, Bangkok, Thailand.

Bergmann, J., and Fiebig, M. (1999). Comparison of experimental and numerical investigation on local and global heat transfer in turbulent square channel flow with roughness elements in the form of V-shaped broken ribs. Flow, Turbul. Combust., 62(2), 163-181. http://dx.doi.org/10.1023/A:1009943429753

Bird, R.B., Stewart, W.E., and Lightfoot, E.N. (2001). Transport Phenomena (second edition). John Wiley and Sons Inc. USA.

Crittenden, J.C., Trussell, R.R., Hand, D.W., How, K.J., and Tchobanoglous, G. (2005). Water Treatment: Principles and Design. John Wiley and Sons, Inc. USA. PMCid:PMC1782057

OpenCFD Limited (2008). OpenFOAM User Guid. www.openfoam. com.

Persson, J. (2000). The hydraulic performance of ponds of various layouts. Urban Water, 2(3), 243-250. http://dx.doi.org/10.1016/S1 462- 0758(00)00059-5

Pope, S.B. (2000). Turbulent Flows. Cambridge University Press. http://dx.doi.org/10.1017/CBO9780511840531

Rodi, W., and Mansour, N.N. (1993). Low Reynolds number k- $\varepsilon$ modeling with the aid of direct simulation data. J. Fluid Mech., 250, 509-529. http://dx.doi.org/10.1017/S0022112093001545

Salter, H., Ta, C., Ouki, S., and Williams, S. (2000). Three dimensional fluid dynamic modeling of a facultative lagoon. Water Sci. Technol., 42, 335-342.

Shilton, A., Kreegher, S., and Grigg, N. (2008). Comparison of computational fluid dynamics simulation against tracer data from a scale model and full-sized waste stabilization pond. J. Environ. Eng., 134(10), 845-850.http://dx.doi.org/10.1061/(ASCE)0733-93 72(2008)134:10(845)

Shilton, A., and Mara, D. (2005). CFD modeling of baffles for optimizing tropical waste stabilization pond systems. Water Sci. Technol., 51, 103-106. PMid:16114670

Sookhak Lari, K., van Reeuwijk, M., and Maksimović, Č. (2010). Simplified numerical and analytical approach for solutes in turbulent flow reacting with pipe walls. J. Hydraul. Eng., 136(9), 626632. http://dx.doi.org/10.1061/(ASCE)HY.1943-7900.0000229

Sweeny, D., Nixon, J., Cromar, N., and Fllowfield, H. (2005). Profiling and modeling of thermal changes in a large waste stabilization pond. Water Sci. Technol., 51, 163-172.

Ta, T. (1997). Application of computational fluid dynamics to water industry. In Proceeding of Fluent Users Conference, Manchester, UK. PMCid:PMC2143690 
Ta, T. (1999). Current CFD tool for water and waste water treatment processes. In Proceeding of 2nd International Symposium on Computation Technology (CFD) for Fluid/Thermal/Chemical Systems and Industrial Applications, ASME PVP Division Conference, Boston.

Tchobanoglous, G., Burton, F.L., and Stensel, H.D. (2003). Wastewater Engineering: Treatment and Reuse. Metcalf and Eddy. USA.

Talvy, S., Cockx, A., and Liné, A. (2007). Modeling of oxygen mass transfer in a gas-liquid airlift reactor. AIChE J., 53(2), 316-326. http://dx.doi.org/10.1002/aic.11075

Van Reeuwijk, M., and Sookhak Lari, K. (2012). Asymptotic solutions for turbulent mass transfer at high Schmidt number. Proc. $R$. Soc. (A Math. Phys. Eng. Sci.), 468(2142), 1676-1695. http://dx. doi.org/10.1098/rspa.2011.0538

Vega, G., Pena, M., Ramirez, C., and Mara, D. (2003). Application of
CFD modeling to study the hydrodynamics of various anaerobic pond configurations. Water Sci. Technol., 48(2), 163-171. PMid:1 4510207

Weigand, B. (2004). Analytical Methods for Heat Transfer and Fluid Flow Problems. Springer, Berlin. http://dx.doi.org/10.1007/978-3540-68466-4

Wood, M., Greenfield, P., Howes, T., Johns, M., and Keller, J. (1995). Computational fluid dynamic modeling of wastewater ponds to improve design. Water Sci. Technol., 31(12), 111-118. http://dx.doi. org/10.1016/0273-1223(95)00498-C

Wood, M., Howes, T., Keller, J., and Johns, M. (1998). Two-dimensional computational fluid dynamic models for waste stabilization ponds. Water Res., 32(3), 958-963. http://dx.doi. org/10.1016/S00 43-1354(97)00316-3 